\title{
LA FILOSOFÍA DEL ROSTRO EN MAX PICARD
}

\section{THE PHILOSOPHY OF HUMAN FACE IN MAX PICARD}

\author{
Catalina Elena Dobre ${ }^{1}$ \\ Universidad Anáhuac, México
}

Recibido 28 agosto 2019

Aceptado 22 septiembre 2019

\begin{abstract}
Resumen: Las reflexiones filosóficas de Max Picard son hoy en día, desafortunadamente, muy poco conocidas. Sin embargo, se trata de un pensador original, con un estilo peculiar y autor de obras filosóficas únicas que influenciaron de manera decisiva en el desarrollo de la filosofía contemporánea, sobre todo en el ámbito de la antropología filosófica y la comprensión de los límites de la modernidad. En estas páginas, el objetivo es un análisis del concepto de rostro, desde una perspectiva antropológica, partiendo de su manifestación como Imago Dei, para demostrar la importancia de este concepto en la comprensión de la persona humana como unidad espiritual y como manifestación de lo eterno en el tiempo.
\end{abstract}

Palabras claves: Rostro, Imago Dei, Imagen, Eternidad, Temporalidad, Modernidad.

\begin{abstract}
Max Picard's philosophical reflections are, unfortunately, very little known in our days. However, it is an original thinker, with a peculiar style and author of unique philosophical works that decisively influenced the development of contemporary philosophy, especially in the field of philosophical anthropology and the understanding of the limits of the Modernity. The focus of this paer is to offer an analysis from an antropological perspective of the concept of the human face, based on its manifestation as Imago Dei, to demonstrate the importance of this concept in the understanding of the human person as a spiritual unity and as a manifestation of the eternal in time.
\end{abstract}

Key words: Human Face, Imago Dei, Image, Eternity, Temporality, Modernity.

1. (katalina.elena@yahoo.com.mx) Doctora en filosofía por la Universidad "Alexandru Ioan Cuza", Iasi, Rumania. Profesora-Investigadora en la Universidad Anáhuac, México. 


\section{Introducción}

Apreciado por Gabriel Marcel como "uno de los pensadores más originales de nuestros tiempos", la paradoja es que, a la vez, Max Picard es uno de los filósofos contemporáneos menos conocidos. Filósofo por vocación y de profesión médico, Picard logra crear un modo de pensar auténtico acompañado siempre de un estilo poético que opone ante el discurso analítico, científico y reduccionista, fundamentado en la propuesta del pensamiento moderno, cuya influencia resultó abrumadora, marcando el inicio de un proceso que acabará en el fracaso del pensamiento filosófico, proponiendo, al mismo tiempo, una filosofía que parte de un diálogo conciliador para recuperar lo humano en el hombre.

Su pensar filosófico tan original inspiró el desarrollo de la filosofía de Emmanuel Lévinas, Gabriel Marcel, Martin Heidegger, Merleau-Ponty, Thomas Merton, Hans Urs von Balthasar, Alfonso López Quintás, entre otros, así como varias obras literarias. Y esto nos autentifica el hecho de que Picard es el creador de una filosofía expresada en una obra poética por excelencia, que puede ser incluida en el ámbito del personalismo filosófico o del humanismo contemporáneo.

Max Picard es uno de los más importantes pensadores en cuanto a la comprensión de la persona humana en su fundamentación antropológica y ética de la modernidad, en su proceso de pérdida de sentido y de la revalorización del mundo entendido como una continuidad misma de Dios. Alfonso López Quintás afirmaba precisamente que en "en la línea de pensamiento - que inspiró en buena medida la antropología filosófica europea del último cuarto de siglo- se mueve Max Picard, escritor suizo que ha vivido siempre en contacto estrecho con la naturaleza y en fidelidad estricta con los ritmos naturales. Sus bellas obras sobre el lenguaje, el silencio, la vida matrimonial, la huida de Dios adquieren a la luz de la interpretación ambital del lenguaje toda su hondura y se elevan muy por encima de la mera literatura edificante"

La filosofía de Picard se enfoca en el hombre, en el rostro humano, en su silencio, en su lenguaje tratando de ofrecernos todas las vías posibles para recrear nuestra humanidad en una cultura deshumanizada y para recuperar todo aquello que sólo el silencio y la contemplación nos pueden enseñar: la relación con lo sagrado. Y lo hace de manera poética, no con-

2. Gabriel Marcel y Max Picard. Correspondance 1947-1965; Paris: Ed. L'Harmattan, 2006, p. 17.

3. Alfonso López Quintás; Estética de la creatividad. Madrid: Ed. Rialp,1998, p. 350.

Thémata. Revista de Filosofía No60 (2019) pp.: 35-48. 
ceptual, invitándonos, mediante su escritura, a vivir un auténtico acto de lectura contemplativa para sentir el silencio de sus palabras.

El objetivo de estás páginas es lograr una comprensión del concepto de rostro en Max Picard, ya que considero importante su aportación para la fundamentación de la persona humana como relación, a través del escrito El rostro humano (Das Menschengesicht) que representa una peculiar reflexión en torno al valor inigualable de la persona humana y su dignidad. Sin un rostro, la persona pierde perdería su identidad, el rostro nos autentifica además de ser lo primero que nos relaciona con los demás. El rostro humano tiene, a diferencia de todo el cuerpo, una peculiaridad: concentra en sí la expresión total del espíritu y expresa, por lo mismo, lo más profundo de la persona humana y esto es lo que queremos resaltar en estas páginas.

\section{Antecedentes conceptuales}

Picard parte en su análisis recobrando el sentido latino de la Bild (Imago), cuya raíz la encuentra un poco incierta, quizás relacionada con la palabra magis (que expresa algo más que la realidad habitual) o magister (el que sabe más que los otros); y como confiesa él mismo, los estudios de la imagen le han llevado unos años ${ }^{4}$. Siendo el rostro una Imago animis (Imagen del alma) es, a la vez, Imago Dei (Imagen de Dios). Dios nos regala su presencia en este rostro humano, mediante el cual se manifiesta, representando este acontecimiento un misterio en sí.

Sobre el concepto de Imago Dei ha corrido mucha tinta, expresando el significado de nuestra humanidad y representando la base del humanismo. Algunos entendiéndolo como la manifestación del espíritu en el hombre y otros reduciendo esta idea a la manifestación de la racionalidad en el hombre. Aún así, una cosa es segura: se trata de entender que la persona humana está intrínsecamente relacionada con lo divino; siendo esta imagen la manera de expresar la presencia de lo eterno en el hombre.

Analizado por San Agustín, o por Santo Tomás de Aquino, así como por varios místicos o teólogos medievales como Eckhart o Nicolás de Cusa, la idea del hombre como Imago Dei ha sido representada en el arte medieval (pinturas y esculturas) para revelar la identidad entre el rostro como imagen de Dios y la personalidad mediante el concepto de agnitio ${ }^{6}$ (un tipo

4. Cf. Gabriel Marcel y Max Picard; Correspondance 1947-1965, cit. p. 119 (Carta de Picard a Marcel del 28 de noviembre de 1951).

5. Gen. 1:26-27

6. Cf. M. E. Moore. "Meditation on the Face in the Middle Ages (with Lévinas and Picard)" en Literature and Theology, Vol. 24, no. 1. 2010, p. 22. www.jstor.org (consultado el 20 de

Thémata. Revista de Filosofía No60 (2019) pp.: 35-48. 
de identidad entre el rostro y el carácter), tratando de enfatizar la relación entre el rostro humano y el sentido ético y espiritual de la humanidad guiada por lo divino.

Max Picard en su escrito El rostro humano, no puede omitir esta influencia que viene de toda la inspiración medieval sobre el tema del rostro humano, ya que estos valores que los medievales identificaron en el rostro humano, se pueden comprender en relación a las cuestiones de la conciencia continua de la humanidad en el mundo moderno ${ }^{7}$.

A diferencia de los pensadores medievales, la comprensión de Picard en relación al tema de Imago Dei es un acercamiento no tanto teológico, sino antropológico que viene a dar un sustento real al ser humano. A pesar de que todo el cuerpo humano revela la presencia de lo divino, Picard elige el rostro humano como la parte más relevante para expresar la presencia de Dios en el hombre. "El que mira un rostro humano se traslada al centro mismo de su ser. Sus emociones, su comprensión, su voluntad se ven afectadas, e incluso hasta lo más profundo de él, donde sus emociones, inteligencia y convivencia coexisten en esa oscuridad sin forma que llamamos presentimiento, se sienten miradas, observadas. Su ser entero esta surcado"8. En esta mirada el rostro se presenta en toda su belleza, pero también en toda su vulnerabilidad.

Aunque Jean-Luc Egger habla de una lectura fenomenológica de la fisiognomía del ser humano en la obra de Picard, su lectura de rostros no siempre es justificable desde el punto de vista conceptual, ni convincente fenomenológicamente ${ }^{9}$, como afirma Lévinas. Por lo mismo, es mucho decir que en Picard tenemos una "fenomenología del rostro". El modo de entender el rostro humano es más poético y místico, porque refleja en sí esta singularidad última que es la huella de Dios en el hombre.

El rostro es el único en el cual se manifiesta esta singularidad, concentrando en sí la presencia del espíritu, expresada después en la mirada. Es en la expresión de nuestro rostro, lo que nos asienta ontológicamente y en la cual se ve reflejada la manifestación entera de nuestra personalidad. Es el rostro en el cual la dignidad cobra forma y sentido, es la ventana mediante la cual nos abrimos al mundo. El rostro humano es la expresión de su interioridad, de la vida del espíritu.

Inspirado no sólo por las reflexiones de los pensadores medievales, pero también por su amigo Rudolf Kassner ${ }^{10}$, autor de un estudio sobre la

marzo de 2019).

7. Cf. Ibídem, p. 20.

8. Max Picard; The Human Face, USA: Cassell and Company Limited, 1993, p. 3.

9. Ibídem, p. 96.

10. Rudolf Kassner (1873-1959): fue un filósofo de la cultura y escritor austríaco, muy cono-

Thémata. Revista de Filosofía No60 (2019) pp.: 35-48. 
fisiognomía, Picard inicia su análisis con una diferenciación de la presencia del rostro:

1. en relación a un mundo sagrado, en el cual el rostro humano todavía tenía marcada la presencia de Dios;

2. un mundo moderno (identificado por Picard con la decadencia que empieza en el siglo XX), en la cual el rostro ha perdido su autenticidad.

Aunque desde la perspectiva de Hermann Hesse, Picard era uno de los más grandes fisiognomistas, el filósofo suizo va más allá que la ciencia de la fisiognomía de la cual deriva la grafología, considerando que el modo en el cual éstas comprenden el rostro humano es desde una perspectiva reduccionista. En una carta a su amigo Karl Pfleger, afirmaba el filósofo suizo:

Además, una cosa es totalmente clara para mí: la grafología, la fisiognomía tienen razón hoy en día; hasta la psicología e incluso el psicoanálisis tienen razón, pero tienen razón sólo porque hoy el hombre no es más que un pedazo de la grafología y un pedazo de fisiognomía y un pedazo de la psicología. Para el residuo humano del cual disponemos hoy, todas estas son válidas ${ }^{11}$.

Con esto Picard quiere resaltar que el rostro se ha vuelto un instrumento de la ciencia que lo ha despojado de su dignidad y de su origen. Para entender de mejor manera qué significa el rostro para Picard es necesario comprender el concepto de imagen. Por lo tanto, ¿qué significa que el rostro humano es imagen (Bild) de Dios?

\section{El rostro como Imago Dei}

Significa que guarda en su expresión un rastro de lo eterno, porque el mismo Dios, como dice Picard, imprime su imagen en el rostro humano. Afirma: "tan pictórico es el rostro humano; es como si Dios no hubiera creado al hombre en absoluto, sino que solo lo hubiera visto en una imagen de ensueño" ${ }^{2}$. El rostro humano es presencia, y tiene que durar en el tiempo para hacer manifiesta la misma presencia de Dios.

La imagen representa el reflejo de lo que intrínsecamente representa nuestra naturaleza como seres humanos; podemos decir, que es el reflejo de nuestra esencia. Considerando la influencia platónica en la filosofía de Picard, Jean-Luc Egger habla con razón de que la imagen es el

cido en la época y nominado tres veces al Premio Nobel de literatura.

11. Max Picard. Briefe and den Freund Karl Pfleger, 48 (en trad. It. da Max Picard, Il rilievo delle cose. Pensieri y aforismi, a cura di Jean-Luc Egger) en Jean-Luc Egger; Dire il silenzio. La filosofia di Max Picard, cit. p. 137-138.

12. Max Picard; The Human Face, cit. p. 10.

Thémata. Revista de Filosofía No60 (2019) pp.: 35-48. 
reflejo de un arquetipo ${ }^{13}$ en sí objetivo, que es la expresión de un mundo originario.

Este arquetipo es Dios. La imagen es participativa a este arquetipo originario, y la participación se refleja en la manifestación misma de la imagen en el rostro. En relación a esto, podemos hablar de un movimiento, ya que la imagen al ser participativa significa que tiene en sí su propia dinámica: se hace presente y con esto, siempre aparece como nueva.

Existe así una "constante regeneración interna" 14 de esta misma imagen. Sólo que me gustaría enfatizar que, aunque con profundos rasgos platónicos (considerando el tema de la participación y del arquetipo o del movimiento), hay una diferencia con el filósofo griego: es decir, para Platón las imágenes (lo que aparentaban) eran meras copias de los arquetipos -ideas- originarios y, por eso, inferiores a las ideas en sí. En el caso de Picard, la imagen no es una copia del arquetipo, pero sí una representación; es más bien el modo en el cual el arquetipo -en este caso Dios- se hace presente de manera singular. La representación en sí es algo que tiene carácter de novedad, de actualización y presencia. Como diría más tarde Hans-Georg Gadamer ${ }^{15}$ en cuanto al concepto de imagen: "El que la representación sea una imagen -y no la imagen originaria misma- no significa nada negativo. (...) Cada representación viene a ser un proceso óntico que contribuye a construir el rango óntico de lo representado. La representación supone para ello un incremento de ser. El contenido propio de la imagen se determina ontológicamente como emanación de la imagen original" 16 .

Aunque es una representación, la imagen tiene una vinculación originaria con lo representado; con el ser y, en el caso de Picard, con Dios.

13. Cfr. Jean-Luc Egger. Dire il silenzio. La filosofia di Max Picard, cit. p. 116.

14. Ibídem, p. 130.

15. Aunque Jean-Luc Egger entrevé una relación en cuanto al tema de la imagen entre Max Picard y Gadamer afirmando: "Picard percibe, como hacen algunos grandes teóricos del concepto de imagen de finales del siglo XIX inicio del siglo XX, que la imagen se caracteriza por un ser fluctuante y abierto a una idealidad (H. G. Gadamer)". Jean-Luc Egger. "L'ultimo dono nello sguardo" en Max Picard; L’ultimo volto dell'uomo. Maschere mortuarie da Shakespeare a Nietzsche, Milano: Ed. Servitium, 2015, p. 77. Sin embargo, Egger no desarrolla esta relación en cuanto el concepto de imagen en Gadamer y Picard. Considerando que Gadamer es posterior a Picard, pudiéramos pensar que había leído su obra, ya que Picard es uno de los pocos filósofos que desarrollan este concepto de Bild en la primera mitad del siglo XX, partiendo de su análisis del ámbito del arte. Se sabe que Gadamer desarrolla precisamente el concepto de imagen con relación al arte y con relación al concepto de juego. Y efectivamente hay una forma de comprender la imagen de manera similar como representación, autonomía y presencia que no anula lo original, el arquetipo al que representa sino más bien siendo una continuidad de éste en la presencia de lo eterno en el tiempo.

16. Hans-Georg Gadamer. Verdad y método, Salamanca: Ed. Sígueme, 1997, p. 189.

Thémata. Revista de Filosofía No60 (2019) pp.: 35-48. 
Esta representación adquiere presencia, porque participa de la imagen originaria; siendo a la vez autónoma. "La imagen es tan original, tan primigenia como la imagen original que representa, porque como manera de representar pertenece al horizonte no develado de la imagen original; no es que sea un aspecto ya conocido del original el que se representa, sino que gracias a esta representación adquiere su ser"17.

Decirlo de otro modo, la imagen en su esencia no es un mero simulacro, sino que representa la clave esencial para la comprensión del espíritu humano. La imagen es lo verdadero que se manifiesta y representa realizándose mediante el espíritu humano y manifestándose en el rostro. Jean-Luc Egger afirmaba en este sentido que en este mundo picardiano, la imagen adquiere una dimensión claramente sustancial, ya que no debe entenderse como un simulacro, sino como una realización perfecta del ser humano en su vocación original ${ }^{18}$.

Hacerse presente, como antes mencionaba, significa manifestar una dinámica propia e intrínseca; es decir, hay una dialéctica participativa que se logra mediante el amor y que implica una apertura total que da a la imagen la posibilidad de renovarse, de ser otra vez sí misma. Es así, que la imagen depende de una elección que se refleja en el rostro como espejo fiel de esta Imago Dei. Picard confesaba años más tarde que la imagen exige de los hombres: tiempo y amor, sin estas dos no puede manifestarse. Necesita del tiempo de la presencia para ser y necesita del amor para comprometerse con la realidad.

En este sentido, las características esenciales del rostro humano, como imagen de Dios, son: la humildad, lo sublime, el reposo, la dignidad, el silencio, el amor y la claridad. Existía, dice Picard, una humildad hermosa que, antes se expresaba en el rostro humano, que reflejaba una síntesis entre lo divino y lo humano; existía un silencio que ofrecía profundidad y durabilidad a este rostro, "es por esa razón, dice el filósofo, que los seres humanos, continuamente representan el rostro humano en piedra (las esculturas). Es como si el rostro que es silencio, en piedra se está rodeando de la manifestación silenciosa de Dios"19. Lo triste es el momento en el cual la imagen deja de ser huella de Dios en el hombre, convirtiéndose en

17. Rafael García Pavón. "La imagen o el ser como presencia en la hermenéutica filosófica de Hans-Georg Gadamer”, en Razón y palabra, abril-mayo (2002), www.razonypalabra.org.mx (consultado el 20 de marzo de 2019).

18. Cf. Jean-Luc Egger. "L’ultimo dono nello sguardo", p. 77.

19. Max Picard; The Human Face, p. 17.

Thémata. Revista de Filosofía No60 (2019) pp.: 35-48. 
una 'pseudoimagen' que, pudiéramos decir, que es una simple copia en un lenguaje platónico.

\section{El rostro como unidad espiritual}

En el rostro humano está presente el misterio de la existencia y, a la vez, la bella claridad. Tiene forma, tiene dimensionalidad y tiene corporeidad, porque el rostro es parte del cuerpo humano y, al mismo tiempo, tiene algo de lo divino. De aquí su misterioso modo de ser, que ninguna ciencia o categoría abstracta puede capturar.

Aunque está hecho de partes distintas (ojos, cejas, nariz, boca, orejas etcétera), el rostro humano es más que la suma de sus partes; representa una unidad que ilumina, porque todas estas partes están relacionadas unas con las otras. Por lo mismo que, un rostro no se puede juzgar por sus partes separadas como intenta hacer por ejemplo la grafología.

Cada parte del rostro humano ha sido puesto en el lugar adecuado para crear una armonía. Es así, como uno puede ofrecer una sonrisa, porque en este sencillo gesto participa todo el rostro humano, ofreciendo y recibiendo emociones, haciendo presente lo divino en el hombre. La unidad del rostro humano, su armonía, es para el filósofo suizo la huella de Dios en el hombre singular. Todo es visible en el rostro humano, sobre todo el alma que está presente en cada parte sin ser apegada a alguna en especial. Afirma Picard:

El alma es una unidad, un todo, y esa expresión del rostro corresponde a que el alma también debe ser uno y todo. Si el alma, por ejemplo, sonríe, todo el rostro sonríe. Por eso, una sonrisa en el rostro no se puede dividir en partes y relacionada con ciertos grupos musculares. La sonrisa se teje en toda la cara y no se puede disecar ${ }^{20}$.

Aun así, el alma no sólo se refleja en el rostro humano, sino en toda la figura, en cada movimiento y en cada reposo. Como bien dice el filósofo, "el alma está en todas las partes", porque es el vínculo originario con lo divino. Más tenga la relación el hombre con lo divino, más mostrará su verdadero rostro sin ocultarlo, más el alma estará presente. Esto no significa que la manifestación del alma exige siempre un rostro perfecto. Puede pasar que, en un rostro no tan armonioso, esté presente un alma hermosa y es precisamente esta alma, la que hace un rostro hermoso. Con una sonrisa, y con la presencia del alma en la sonrisa, un rostro no tan armónico puede devenir el más bello. Ahí está la presencia del misterio, en esta transformación, en esta flexibilidad de un rostro, que se puede trans-

20. Ibídem, pp. 54-55.

Thémata. Revista de Filosofía No60 (2019) pp.: 35-48. 
formar cuando tiene presencia. Tener presencia significa estar conectado con lo divino, pero también con los otros seres humanos.

En el rostro están plasmadas nuestras posibilidades de devenir, de realización de sí mismo, así como están plasmadas nuestras posibilidades de relacionarnos. La sonrisa, por ejemplo, sería un puente de vínculo con otro rostro humano. Cuando un rostro humano está cerca de otro rostro humano, ahí está la posibilidad de la comunión, de encuentro, sin que cada rostro pierda su peculiaridad. Como bien dice Picard: "cuando un hombre se encuentra con otro, su alma primero debe separarse del encuentro eterno para venir al encuentro humano" ${ }^{21}$, hay algo en este encuentro, que hace a cada uno recordar algo de su origen divino.

La manifestación de la creación y del alma en el rostro humano, es decir el encuentro, se da sólo cuando el hombre se dirige a sus semejantes. "Un alma que no está en relación con la otra alma es incapaz de expresar su naturaleza pictóricamente en el rostro" 22 afirma Picard, recordando lo que Martin Buber decía sobre la posibilidad del encuentro, que se da sólo cuando un yo está presente ante un Tú. Encontrarse significa tener la capacidad de responder a lo que tenemos frente a nosotros. Cuando nos privamos de este gran privilegio del encuentro ya perdemos nuestras conexiones con el presente. Y lo que se tiene ante nosotros, desde la perspectiva del filósofo suizo, es un rostro que no limita, sino que nos hace entender nuestra propia libertad.

El hombre puede estar en la cercanía de otro hombre o de otro ser vivo, porque su rostro guarda la presencia de la imagen de Dios en el momento de la creación. Para Picard el hombre es parte de esta bella creación, no está por encima de ella; al contrario, es el ser más responsable porque, mediante su rostro, se vuelve el intermediario entre la creación y Dios mismo. Es por eso que toda la naturaleza está reflejada en el rostro humano y mientras cuidamos y preservamos la naturaleza, estaremos cerca de Dios. Destrozarla significa mutilar nuestro propio rostro, nuestra alma y con ella nuestra esencia como personas y manifestar una total falta de trascendencia.

Esta Imago Dei con la cual el ser humano viene ya dotado en su rostro, como el más hermoso regalo, implica también una responsabilidad que se tiene que llevar a cabo en el modo de ser del hombre con los demás y con la entera creación. Es por lo mismo que un rostro humano revela su verdadera belleza sólo en la comunidad; ahí cuando está frente a frente con otro rostro humano. El verdadero valor del rostro humano se muestra

21. Ibídem, p. 147.

22. Ibídem, p. 87.

Thémata. Revista de Filosofía No60 (2019) pp.: 35-48. 
sólo en la comunidad y aquí empieza la labor ética, porque estar ante un rostro representa una invitación para actuar de manera responsable.

\section{Rostro-máscara: la pseudoimagen}

A pesar de toda esta apología de la belleza de rostro humano, Max Picard también admite la existencia de almas malvadas que son la expresión de lo demoníaco en el hombre. Para el filósofo suizo esto se entiende muy bien en un análisis de fondo de los rostros de nuestros tiempos, que expresan vacío en lugar de presencia de Dios; porque son rostros ruidosos, rostros fantasmas, en los cuales se ven reflejados el miedo y la desconfianza; rostros fríos que han perdido el humor; tan es así, que hoy en día el rostro humano ya no quiere ser imagen de Dios. En una carta dirigida a Gabriel Marcel confesaba:

Nuestro mundo está sin imagen; los hombres han perdido la fuerza que emana de la imagen; el hecho de que los hombres estén juntos ya no tiene tampoco una gran virtud, porque carecen de rostro, de gestos, de carácter, y han perdido la posibilidad de convertirse en una imagen, en un retrato, en una semejanza y en el alma misma. $\mathrm{Y}$, por supuesto, lo somático comienza a dominar: los genes y el peso de la herencia toman el ritmo y eso es lo que ahora da forma al hombre. Y ni siquiera es un problema si las teorías científicas de la herencia, desaparecen la Imagen ${ }^{23}$.

En los rostros de hoy las posibilidades de relación están aniquiladas, porque se ven como si nunca hubieran experimentado nada en sus vidas, como si fueran irreales, abstractos, mera combinación genética y nada más. Un rostro sin imagen, pero sí "moldeado" por la ciencia. No extraña que el hombre de hoy vive de modo abstracto sin implicación alguna, sin empatía, sin ser capaz de relacionarse con los otros de verdad, sin un corazón que se viera reflejado en sus rostros. Por eso, el rostro se vuelve una máscara; un ocultamiento de lo demoníaco que habita en su alma y que es una mera apariencia, una pseudoimagen. Como bien afirma Picard: "El hombre de hoy, que siempre está en camino, -que siempre está como en una batalla-, un fugitivo, llevaría consigo siempre los símbolos ligeros de las cosas en lugar de las cosas difíciles" ${ }^{24}$.

Así como Kierkegaard una vez que hablaba del engaño y de la desesperación, Picard también advierte que, en un momento, las máscaras se caen y el rostro está exigiendo mostrarse: allí es cuando no hay manera de ocultarse más. El rostro es lo auténtico en la persona y más lo enmascaramos, más su desocultamiento será doloroso, porque se revelará un rostro

23. Gabriel Marcel y Max Picard; Correspondance 1947-1965, cit. p. 96 (Carta de Picard a Marcel del 3 febrero de 1950).

24. Max Picard; The Human Face, p. 75.

Thémata. Revista de Filosofía №6 (2019) pp.: 35-48. 
distorsionado que le hará a uno pensar que el alma está desesperada, que está buscando una fisura por dónde pudiera escapar ${ }^{25}$.

Un rostro-máscara será incapaz de estar frente al otro, porque carecerá de valor, de autenticidad. Por eso ya no existe la comunidad o no hay como crearla a través de rostros-máscaras. Afirmaba Picard en este sentido: "Hoy, cuando falta la comunidad y el hombre, amputado de todo, es visto por otros que están tan aislados como él; hoy en día son precisamente los signos de desmembramiento e individualización los que se reflejan más prominentes en la cara"26.

Hoy en día todos viven aislados, para sí mismos nada más, descuidando que las personas se pueden renovar a sí mismas solo en la comunidad. De esta manera los rostros humanos se muestran como un resultado de las circunstancias. "A veces nos parece que el arte, la ciencia y las filosofías de hoy son intencionalmente tan relativistas, para que nuestro rostro relativo parezca justificado por un entorno donde todo es, igualmente, relativo. El rostro de hoy ha creado ese mundo actual para poder legitimarse a sí mismo"27, afirma Picard. Tan es así que, en nuestros días, los rostros humanos aceptan todo, de tal manera que se vuelven una colección caótica de expresiones; rostros petrificados por el miedo.

Actualmente los rostros humanos son demasiado visibles, ya no están rodeados de silencio y no pueden más expresar el silencio. El rostro humano hoy ya no se relaciona con el tiempo y con el presente. La presencia es fundamental para el rostro humano ya que "la presencia siempre le da fuerza al hombre, porque el hombre cuando está presente se detiene ahí donde Dios se detuvo" 28 .

\section{Rostro, temporalidad y eternidad}

Según el filósofo suizo el rostro humano tiene realidad sólo cuando refleja lo divino. Si el rostro humano está presente, Dios también está presente. Y esta realidad del rostro surge cuando al hombre lo envuelve el silencio, que es la casa de su ser. Ahí es dónde se revela su singularidad. Para Picard, la persona humana es un ser singular, sin embargo, no diferente.

El problema de la "diferencia", en el modo en el cual la plantea el filósofo suizo, viene como un contra-argumento a los defensores de lo que hoy en día entendemos por diferencia. Pensamos que entre más diferente

25. Cf. Ibídem, p. 67.

26. Ibídem, p. 94.

27. Ibídem, p. 102.

28. Ibídem, p. 122.

Thémata. Revista de Filosofía No60 (2019) pp.: 35-48. 
se es al otro, más peculiar y es así como tejemos, sin darnos cuentas barreras que los demás ya no pueden traspasar. Queremos ser tan diferentes que llegamos a un aislamiento total y olvidamos completamente, como sostiene Picard, que la "diferencia" no es más que un signo de la multiplicidad de Dios; en el fondo, un signo de la unidad; es decir, ser yo mismo es lo que me une con el otro:

Hoy el individuo considera que su diferencia le pertenece sólo a él, y teme que se olvidará de sí mismo si no fuera muy diferente de los demás. Emplea su diferencia como si fuera un signo para recordarse a sí mismo. Sin embargo, antes, todos los rostros se pensaban como preservados en la memoria de Dios; mientras que ahora cada rostro busca sólo preservarse, es por eso que debe trazar distancias desde su propio rostro ${ }^{29}$.

Sólo los adultos son capaces de entender su peculiaridad en relación a la diferencia, porque el rostro de un niño siempre preservará la unidad. Los niños, de manera natural se relacionan sin prejuicios, sin barreras. Normalmente cuando entre los niños surgen barreras es porque han intervenido en sus mundos los adultos que los llenan de prejuicios. Pero, el niño refleja en su rostro la apertura de ir al encuentro con el otro. Los niños siempre están unidos, como sostiene Picard, ni el tiempo, ni el espacio los separan.

El rostro humano tiene una parte visible, pero también una invisible y es en esta última, en la cual se tejen los signos del tiempo. En la presencia lo invisible se hace visible porque el rostro humano se pone a sí mismo en una situación de contemporaneidad, como afirma Picard. El rostro humano está en una situación de contemporaneidad cuando expresa el encuentro entre el tiempo y lo eterno. Porque, cuando el rostro humano se mueve en la temporalidad siempre expresará algo de lo eterno.

Afirma Picard: "el ojo de un hombre es ese lugar en el cual la eternidad llegó lo más lejos en el presente. El ojo es como la última pared delgada y translúcida, la división final entre el presente y la eternidad. Cuando el ojo se cierra, es como si la eternidad regresara en sí misma" ${ }^{30}$. El ojo, la mirada, representan un puente entre lo temporal y lo eterno. Sin la cercanía de la eternidad, sin el reflejo de esta, el rostro humano sería invisible, sin expresión, vacío. La temporalidad no es el tiempo en su linealidad, sino la conciencia de estar presente ante el horizonte de posibilidades; en otras palabras, es la conciencia de un devenir constante.

La presencia (Gegenwärtigkeit) es para Picard un momento de eternidad, lo que recuerda la categoría de instante (Øjeblikket) de Kierkegaard, en donde la eternidad entra en contacto con el tiempo y lo transfor-

29. Ibídem, p. 182.

30. Ibídem, p. 117.

Thémata. Revista de Filosofía No60 (2019) pp.: 35-48. 
ma de un tiempo lineal a un devenir, a una temporalidad. El instante no es un momento más en una disposición lineal, sino que el instante carga consigo el peso de la eternidad; es en el fondo el devenir de la eternidad en la temporalidad. Lo mencionaba por primera vez Platón y San Agustín, pero Kierkegaard da al instante un sentido más antropológico que metafísico. Afirma: "Lo que nosotros llamamos el instante, lo llama Platón exaíphnes. Cualquiera que sea la clave etimológica de esta expresión, sin embargo, siempre estará en relación con la categoría de lo invisible"31.

Lo que quiero decir es que para Picard, igual que para Kierkegaard, el tiempo sin la eternidad sería un mero vacío. La presencia, este instante en el tiempo, es la vivencia del hombre como conciencia de estar en el tiempo, que para el filósofo suizo se expresa en el rostro que puede estar ante nosotros con una presencia tan imponente, en donde el futuro y el pasado están como atrapados en ella. "Cuando la eternidad entra en contacto con el tiempo es como si se quisiera detener el tiempo, hacerlo pleno (...)"32, como afirma Rafael García Pavón. Es la presencia reflejada en el rostro lo que hace que el pasado y el futuro se unan en ella, porque la presencia misma es devenir y esto hace que el rostro tenga continuidad en el tiempo.

¿Por qué es tan importante esta presencia? Porque, como el mismo filósofo afirma, el hombre sólo se puede renovar en el tiempo como una relación de presente, pasado y futuro. Renovarse en el tiempo significa, como diría el mismo Kierkegaard, elegirse a sí mismo en el tiempo ${ }^{33}$ : una acción que implica no sólo conocerse como objeto; significa acción e implica devenir en el tiempo y una apropiación del tiempo. En otras palabras, es una transfiguración de la interioridad, es presencia. Sólo estando presente, o siendo presencia, uno tiene un punto de partida para el futuro y una referencia para los recuerdos (es decir, con el pasado). Tener presencia hace que el hombre tenga la capacidad de edificarse a sí mismo sobre el tiempo y el espacio, amar y entregarse a los otros. Afirma Picard:

Ya no estamos presentes porque ya no tenemos tiempo. El tiempo es de hecho el curso en el instante, el tiempo es conexión. Todo esto es lo opuesto a la atomización. El hombre atomizado no tiene miedo porque no tiene amor. El amor y el tiempo, de

31. Ibídem, pp. 161-162.

32. Rafael García Pavón. Filosofía cinemática como ética del porvenir: recuperar y recomenzar el tiempo perdido, Roma: IF Press, 2018, p. 111.

33. Muy en breve, para Kierkegaard, elegir ser sí mismo, ni es una prescripción definida de lo que ya hemos sido, de nuestra historia, ni es una arbitrariedad de ser lo que se nos ocurra ser; elegir ser sí mismo implica una dinámica, un movimiento, un devenir, una transfiguración de lo dado en nosotros mismos en relación con nuestras circunstancias concretas. Así, para cada ser humano, la personalidad tiene continuidad en la medida en que los individuos pueden existir como personas, es decir, teniendo esa relación dialéctica y dialógica entre su pasado y su porvenir.

Thémata. Revista de Filosofía No60 (2019) pp.: 35-48. 
hecho, se pertenecen el uno al otro. El hombre que ama se detiene frente a los demás y frente a las cosas y les da tiempo, las contempla. El amor es esto. Repito: el amor y el tiempo son co-pertenecientes. Por amor, Dios envió a su Hijo en el tiempo. ${ }^{34}$

He aquí la clave de qué significa para Picard ser persona como rostro: significa tener presencia, porque mientras estamos presentes ante los demás tendremos la capacidad de amar. Cuando perdemos la presencia, como vivimos en la mera fugacidad, cuando lo superfluo se extiende más sobre nosotros, transformando nuestros rostros en fantasmas del anonimato, y nuestras almas en un mero mecanismo, nos hemos perdido en la fragmentación y olvidamos completamente qué significa amar y ser amado. La fisiognomía del hombre automatizado, del hombre que no tiene un compromiso real con el tiempo -y por ende con el amor-, no refleja ya una respuesta interior; es decir, el rostro no refleja interioridad.

$\mathrm{Al}$ perder la relación con el tiempo, el hombre ya no tiene presencia, porque ignora el compromiso con lo eterno. Estar comprometido con la eternidad es tener conciencia de tu presencia en el tiempo; estar en el tiempo como un rostro que expresa en su mirada la presencia de Dios en el tiempo. Sin embargo, como afirma Picard con tristeza:

Hoy existe un vacío ahí donde alguna vez estuvo la presencia; hoy el pasado y el futuro son mecánicamente arrastrados a este vacío, es más, empujados casi con fuerza hacia él. Y en este vacío sufren un cambio. Es un pasado falso y un futuro falso que se muestran ahí donde ya no hay presencia $^{35}$.

Para resaltar todavía más la importancia de la presencia para el ser humano, Picard hace una comparación con el animal que, desde su punto de vista, no tiene presencia; porque un animal, lo más que queramos no es un espíritu, porque no tiene conciencia de la temporalidad. El animal siempre espera una confirmación por parte del hombre, quiere estar en su cercanía. El rostro de un animal, sólo quiere estar en la cercanía del rostro humano, como bien dice nuestro filósofo. Por eso un animal puede estar esperando en silencio.

Para los animales el tiempo es sólo un flujo, porque ellos mismos están en este proceso de fluir en el tiempo. Sin embargo, como sostiene el filósofo suizo, cuando un hombre pierde presencia ya no tiene rostro ni para relacionarse con Dios, ni con los otros, ni con los animales. Por eso es tan importante la presencia como lo eterno en el tiempo. La presencia es relación, es estar presente y vinculado con la realidad. Como afirma también Jean-Luc Egger, la presencia es el momento en el que toda instru-

34. Max Picard; L'atomizzazione della persona, cit. p. 190.

35. Max Picard; The Human Face, cit. p. 123. 
mentalización o reducción de la persona da paso a la plena manifestación de la otredad en toda su riqueza ${ }^{36}$.

Un rostro que tiene presencia refleja una bella mezcla de tiempo, eternidad y resistencia. Es por lo mismo que un rostro humano, aunque se transforma con cada año, es decir, aunque envejece y se vuelve muy viejo, aún así puede guardar su frescura si tiene presencia. No obstante, como afirma nostálgico Max Picard, donde no hay tiempo no hay esperanza y tampoco memoria ${ }^{37}$. Y donde hay esperanza y memoria también hay espera, hay paciencia.

Hoy en día hemos pervertido el tiempo, lo hemos despojado de presencia y de eternidad. Nadie tiene tiempo para esperar, hemos perdido la paciencia. Nuestra relación con la inmediatez es tan fuerte que no nos damos cuenta que esto va degradando nuestra naturaleza, que necesita de tiempo para poder tener continuidad, presencia y resistencia. El tiempo ha sido arrancado de su lugar y, por lo mismo, el hombre sólo vive en un espacio sin tiempo; y no se da cuenta que así no puede ser sí mismo. "El hombre requiere del tiempo. El hombre se establece en el espacio, es verdad, pero sólo en el tiempo puede esta configuración en el espacio adquirir significado" ${ }^{38}$. Pero cuando se elimina el tiempo, surge un peligro inminente: se elimina también el espacio, también se borra la memoria, las tradiciones y la sabiduría misma, como lamentaba el filósofo ${ }^{39}$.

Mientras más se ignora el tiempo, más dejará de tener presencia y el hombre vivirá fragmentado en un espacio vacío. Hoy en día lo podemos identificar con el espacio de las grandes metrópolis, en las cuales surgen nuevos prototipos de rostros, que Picard analiza en parte: el rostro del profesionista, del capitalista, el rostro del trabajador, o del hombre pobre, del funcionario; rostros que pierden sus presencias en el vasto ámbito del anonimato.

Como una conclusión de esta hermosa poesía del rostro humano es que, para Max Picard, la persona humana se define por su rostro que refleja la presencia misma de Dios (Imago Dei) en el mundo. Sin el espíritu del hombre, la imagen en sí no tendría ningún sentido. El hombre y la imagen representan una unidad antropológica, imposible de separar, ya que la imagen tiene el papel de hacer visible el mundo interior del espíritu humano y su vínculo con la realidad originaria.

La presencia de la imagen tiene un sentido, tanto antropológico, como ético, ya que como el rostro es Imagen de Dios, la presencia de lo divino en la persona humana representa nuestra vía de redención. Como afirma el filósofo:

36. Jean-Luc Egger; Dire il silenzio. La filosofia di Max Picard, cit. p. 113.

37. Cf. Max Picard; The Human Face, p. 139.

38. Ibídem, p. 140.

39. Cf. Gabriel Marcel y Max Picard; Correspondance 1947-1965, cit. p. 151 (Carta de Picard a Marcel de 14 de julio de 1954). 
"en cualquier momento, en cualquier rostro, lo divino puede manifestarse a sí mismo; como eso es así, cada rostro puede ser transformado por lo divino, incluso la cara más baja es más de lo que parece ser" ${ }^{40}$. Es por lo mismo que el ser humano tiene que luchar por preservar esta presencia, la imagen, como un regalo contra la mecanización del rostro reflejada por el progreso y la tecnología que nos deshumaniza y que representa la invasión del mal.

\section{En lugar de conclusiones: Lévinas y Picard}

En el pensamiento contemporáneo es Emmanuel Lévinas, el filósofo que reconocemos de inmediato cuando se trata del concepto del "rostro", así como lo menciona también Michael Edward Moore ${ }^{41}$; esto, porque efectivamente el rostro es fundamental para la comprensión moderna de la persona humana. De una lectura atenta sobre el concepto de rostro en Lévinas, observamos que la mayoría de los intérpretes destacan este "phylum fenomenológico" de Lévinas en relación a Husserl y Martin Heidegger combinado con su "phylum" judío ${ }^{42}$, sin conocer la influencia decisiva que Max Picard tuvo sobre el filósofo francés.

Es el momento de enfatizar brevemente sobre esta influencia decisiva que Lévinas reconoce y admira. En una conferencia-homenaje a Max Picard del año 1966, el filósofo francés hacía pública esta influencia marcada por la lectura, pero también por la correspondencia entre ambos. Afirmaba Lévinas: "Nunca me encontré con Picard, pero tengo la impresión de haber visto su rostro. Para mí, hablar sobre Picard es casi como evocar una aparición, pero extrañamente real. Esa es quizás la definición misma de una experiencia poética. (...) Con Max Picard uno tenía la impresión de que el contacto que mantuvo contigo era aún más importante que el contenido que comunicaba, que la voz era tan importante como el mensaje. Todo su ser estaba ahí en persona, frente a la mía" ${ }^{3}$.

Picard fue para Lévinas una "presencia" decisiva, aunque nunca se encontraron más que en las palabras que intercambiaron en las cartas, que alimentaron de una manera la filosofía de Lévinas, así como él mismo reconoce, afirmando que la reflexión del filósofo suizo sobre el rostro es un "análisis poético" y no tanto fenomenológico. Lévinas mencionaba que leer las reflexiones de

40. Max Picard; The Human Face, cit. p. 217.

41. Cf. Michael Edward Moore. "Meditation on the Face in the Middle Ages (with Lévinas and Picard)" en Literature and Theology, Vol. 24, no. 1. 2010, p. 19. www.jstor.org (consultado el 20 de marzo de 2019).

42. Como por ejemplo en el artículo de Olivia Navarro, "El rostro del otro: una lectura de la ética de la alteridad de Emmanuel Lévinas", Contrastes. Revista Internacional de filosofía, vol. XVIII, 2008, p. 178 www.dialnet.uniroja.es (consultado el 26 de marzo de 2019).

43. Emmanuel Levinas. Proper Names, cit. p. 94 
Picard sobre el rostro ayuda a uno sentirse vivo, ${ }^{44}$ porque lo que uno encuentra en la obra del pensador suizo es "una filosofía del rostro". Es el escrito El rostro humano (Das Menschengesicht), el que llamará la atención a Lévinas quien, fascinado por la escritura de Picard, afirmaba:

En Picard, más allá de un interés general por el hombre, hay un interés por cada rostro humano. Una filosofía del rostro: eso es lo esencial de Max Picard. El rostro no es sólo otro nombre para la personalidad; sino que es la personalidad, pero en su manifestación, su exteriorización y recepción; en su franqueza original. El rostro es en sí mismo y, si puedo expresarlo así, el misterio de toda claridad, el secreto de toda apertura ${ }^{45}$.

Para Lévinas el rostro (visage) representa la fuente de su planteamiento ético. En síntesis: para el filósofo judío la presencia del rostro del otro implica y requiere un deber moral para con el otro, que requiere una responsabilidad infinita. Este énfasis ético del concepto de rostro en Lévinas, se entiende, sobre todo, porque, a diferencia de Picard, Dios está ausente. La humanidad misma es signo de la ausencia de Dios y, por lo tanto, el hombre es un extraño en el mundo, en su rostro mostrándose esta vulnerabilidad. Ante esta ausencia, el hombre solamente tiene al otro, su humanidad misma realizándose ante el rostro del otro. Desde la perspectiva del filósofo francés el rostro del otro representa la fuente y la realización de la ley moral; y, de una manera, una imagen de Dios, pero sólo como huella ${ }^{46}$ precisamente por la ausencia. Es decir, más que imagen, para Lévinas el rostro es huella de lo absoluto, del infinito de la otreidad, inserta en la totalidad del mundo.

Siendo el rostro la parte más desnuda de la corporeidad, Lévinas resalta la idea de vulnerabilidad que está mediando la relación con otro; siendo así el rostro-ante-rostro un encuentro de dos vulnerabilidades que se necesitan mutuamente ser acogidas de manera recíproca. Picard también reconoce la vulnerabilidad del rostro siendo la parte más expuesta de nuestra corporeidad.

Ahora bien, a diferencia de Max Picard, Lévinas es un pensador formado, para decirlo así, en la tradición judaica y conforme a la misma, la humanidad representa la imagen divina de la creación, pero no es una imagen de culto. Es decir, en la tradición judaica no se acepta la idea de una representación humana de Dios. Picard, aunque judío de origen, fue un pensador converso, atraído por el tema del misterio de la Encarnación. Su conversión al cristianismo, lo ha determinado a tener otro tipo de comprensión del concepto de Imago

44. M. Craig. Lévinas and James: Toward a Pragmatic Phenomenology, Indianápolis: Indiana University Press, 2010, p. 180.

45. Emmanuel Levinas; Proper Names, p. 95.

46. Ibídem, p. 31. 
Dei y, por ende, del concepto de rostro, partiendo de la idea de que ser Imagen de Dios no significa ser un ícono de Dios.

Según Picard, el rostro como imagen es la manifestación divina en el hombre, es esta presencia, es la revelación. El rostro es para Picard la prueba metafísica de la existencia de Dios, sobre todo porque estaba convencido de que en el rostro habita lo divino. Esto no significa de ninguna manera que el hombre es como Dios; sino que el rostro es el habitat, es el hogar en el cual lo divino se deja entrever y se hace presente.

Es con razón que Gabriel Marcel hablaba de una "metafísica de la imagen" en el pensamiento de Picard, en el rostro humano llevándose a cabo la batalla decisiva. Afirmaba Gabriel Marcel: "la imagen - el término Bild también se refiere a la imagen, al retrato - es el silencio que habla. La imagen es como una estación en el camino que conduce del silencio a la palabra, y despierta en el hombre el recuerdo de un modo de existencia antes de la palabra, despierta la nostalgia de esta forma de existencia" 47 .

Con el concepto de rostro, Max Picard quiso enfatizar lo único e irremplazable del ser humano, en el cual se ve reflejada toda la personalidad en una sola y única imagen, en la cual lo divino elige manifestarse a sí mismo.

\section{Bibliografía}

Craig, M.: Lévinas and James: Toward a Pragmatic Phenomenology. Indianápolis: Indiana University Press, 2010, p. 180.

Egger, J. L.: Dire il silenzio. La filosofia di Max Picard. Trento (Italia): Ed. Il Margine, 2014.

Gabriel, M. y Picard M.: Correspondance 1947-1965. Paris: Ed. L’Harmattan, 2006.

Gabriel, M.: "Max Picard o u le retour à l'originel" en La Nef, n. 46, 1948.

Gadamer, H. G.: Verdad y método. Salamanca: Ed. Sígueme, 1997.

García, Pavón R. "La imagen o el ser como presencia en la hermenéutica filosófica de Hans-Georg Gadamer", en Razón y palabra, abril-mayo (2002), www.razonypalabra.org.mx (consultado el 20 de marzo de 2019).

García, Pavón R.: Filosofía cinemática como ética del porvenir: recuperar y recomenzar el tiempo perdido. Roma: IF Press, 2018.

Lévinas, E.: Proper Names. Stanford: Stanford University Press, 1996.

Moore, M. E.: "Meditation on the Face in the Middle Ages (with Lévinas and

47. Gabriel Marcel. "Max Picard o u le retour à l'originel" en La Nef, n. 46, 1948, 32-33. 
Picard)" en Literature and Theology, Vol. 24, no. 1. 2010. www.jstor.org (consultado el 20 de marzo de 2019).

Navarro, O.: "El rostro del otro: una lectura de la ética de la alteridad de Emmanuel Lévinas", Contrastes. Revista Internacional de filosofía, vol. XVIII, 2008, www.dialnet.uniroja.es (consultado el 26 de marzo de 2019).

Picard, M.: The Human Face. USA: Cassell and Company Limited, 1993.

Picard, M.: L'ultimo volto dell'uomo. Maschere mortuarie da Shakespeare a Nietzsche. Milano: Ed. Servitium, 2015.

Picard, M.: L'atomizzazione della persona, trad, en italiano de Franceso Ghia en Come all'inizo del mundo. Il pensiero di Max Picard. Editado por Silvano Zucal y Daniele Vinci. Pontificia Facoltà Teologica di Sardegna: Ed. Il Pozzo di Giacobbe, 2011.

Picard, M.: Man and Language. (Der Mensch und das Wort) trad. Stanley Godman, Chicago: Ed. Gateway, 1963.

Picard, M.: The Human Face. USA: Ed. Cassell and Company Limited, 1931.

Quintás, A. L.: Estética de la creatividad. Madrid: Ed. Rialp,1998. 
